\title{
Synapse-specific Lrp4 mRNA enrichment requires Lrp4/MuSK signaling, muscle activity and Wnt non-canonical pathway
}

\author{
Hongyang Jing ${ }^{1,2 \dagger}$, Peng Chen ${ }^{1,2 \dagger}$, Tiankun Hui ${ }^{1,2}$, Zheng Yu ${ }^{1,2}$, Jin Zhou ${ }^{1,3}$, Erkang Fei ${ }^{1,2}$, Shungi Wang ${ }^{1,2}$, \\ Dongyan Ren ${ }^{1,2}$, Xinsheng Lai ${ }^{1,2^{*}}$ (ID and Baoming Li $\mathrm{Li}^{1,2,4^{*}}$
}

\begin{abstract}
Background: The neuromuscular junction (NMJ) is a peripheral synapse critical to muscle contraction. Like acetylcholine receptors (AChRs), many essential proteins of NMJ are extremely concentrated at the postjunctional membrane. However, the mechanisms of synapse-specific concentration are not well understood; furthermore, it is unclear whether signaling molecules critical to NMJ formation and maintenance are also locally transcribed.

Results: We studied the $\beta$-gal activity encoded by a lacZ cassette driven by the promoter of the Lrp4 gene. As reported for $L$ rp4 mRNA, $\beta$-gal was in the central region in embryonic muscles and at the NMJ after its formation. However, $\beta$-gal was no longer in the central areas of muscle fibers in Lrp4 or MuSK mutant mice, indicating a requirement of Lrp4/MuSK signaling. This phenotype could be rescued by transgenic expression of LRP4 with a transmembrane domain but not soluble ECD in Lrp4 mutant mice. $\beta$-gal and AChR clusters were distributed in a broader region in lacZ/ECD than that of heterozygous lacZ/+ mice, indicating an important role of the transmembrane domain in Lrp4 signaling. Synaptic $\beta$-gal activity became diffused after denervation or treatment with $\mu$-conotoxin, despite its mRNA was increased, indicating synaptic Lrp4 mRNA enrichment requires muscle activity. $\beta$-gal was also diffused in aged mice but became re-concentrated after muscle stimulation. Finally, Lrp4 mRNA was increased in C2C12 myotubes by Wnt ligands in a manner that could be inhibited by RKI-1447, an inhibitor of ROCK in Wnt non-canonical signaling. Injecting RKI-1447 into muscles of adult mice diminished Lrp4 synaptic expression.
\end{abstract}

Conclusions: This study demonstrates that synapse-specific enrichment of Lrp4 mRNA requires a coordinated interaction between Lrp4/MuSK signaling, muscle activity, and Wnt non-canonical signaling. Thus, the study provides a new mechanism for Lrp4 mRNA enrichment. It also provides a potential target for the treatment of NMJ aging and other NMJ-related diseases.

Keywords: Lrp4, Neuromuscular junction, $\beta$-gal, Muscle activity, Wnt non-canonical signaling

\section{Background}

The neuromuscular junction (NMJ) is a chemical synapse between motor nerve terminals and skeletal muscle fibers. It is critical to motoneurons' control of muscle

*Correspondence: laixinsheng@ncu.edu.cn; bmli@hznu.edu.cn

†Hongyang Jing and Peng Chen contributed equally to this work

${ }^{1}$ School of Life Science, Nanchang University, Nanchang 330031, China

Full list of author information is available at the end of the article contraction. Located in the middle of the muscle fibers, NMJs occupy only one-thousandth of a muscle fiber's surface. Yet, essential proteins for NMJ structure and function are highly concentrated at the post-junctional membrane. For example, the acetylcholine receptor (AChR) is concentrated at $10-20,000 / \mu \mathrm{m}^{2}$, a hallmark of the NMJ $[1,2]$. This is thought to be achieved by at least two mechanisms. First, AChR proteins or small AChR clusters distributed along the muscle membrane 
become aggregated in response to agrin, a factor released by motor nerves. Agrin binds to LRP4, activates MuSK, and via Dok7 and rapsyn, mediates AChR clustering [3-7]. Mutation of the gene encoding each of these proteins prevents mice from forming the NMJ [8-11]. On the other hand, synaptic proteins, including the AChR, are synthesized locally at the NMJ. For example, mRNAs of AChR subunits, rapsyn and AChE are enriched at the NMJ [12-18]. Studies using transgenic mice have shown that the regulatory elements of $\mathrm{AChR}$ genes can direct the expression of reporter genes at the NMJ [18-21]. These results strongly support the notion that AChR genes are transcribed locally in subsynaptic nuclei of multinucleated muscle fibers. However, mechanisms underlying the synapse-specific transcription remain unclear. Ectopic expression of agrin or MuSK increased AChR mRNAs in non-synaptic regions [22-24]; however, treatment of muscle cells with agrin increased $\mathrm{AChR} \varepsilon$ mRNA but had little effect on AChR $\alpha$ and $\delta$ mRNA levels in vitro [25], suggesting the involvement of additional mechanisms.

Lrp4 is a member of the LDL receptor family. It possesses a large extracellular domain (ECD) consisting of one LDL $\alpha$ domain, four $\beta$-propeller domains, and a few EGF-like domains between LDLa and $\beta$-propeller domains; a transmembrane domain; and a small intracellular domain (ICD). In the absence of agrin, it could bind to MuSK to maintain a basal activity $[5,6]$. The agrin-Lrp4 interaction increases its binding with MuSK and thus activates the kinase [4-6]. Being a receptor for agrin, it is required for nerve-induced clusters [8, 26, 27]. In addition, LRP4 null mice fail to form primitive, aneural AChR clusters (i.e., before innervation) [8], suggesting that it is necessary for early postsynaptic differentiation of NMJ. Intriguing, Lrp4 mRNA is enriched in the central of muscle fibers in mouse E14.5 embryos and adults $[8,28]$. An interesting question remains what the mechanisms that control the expression of Lrp4 are? Because aneural AChR clusters form in advance of innervation, LRP4 expression is likely to be regulated by a mechanism independent of neural agrin.

This study explored the mechanisms that control Lrp4 expression during development, after denervation, and in aged mice. Because of the lack of reliable antibodies for Lrp4, we studied Lrp4-lacZ mice where the Lrp4 gene was replaced with a cassette containing the lac $Z$ gene. Under the control of the Lrp4's endogenous promoter, $\beta$-gal expression is thought to faithfully indicate where Lrp4 is expressed $[29,30]$. We found that $\beta$-gal expression was concentrated in the middle regions where aneural AChR clusters are located at E13, i.e., before innervation [31, 32], suggesting an innervation-independent mechanism to restrict LRP4 expression within the central region. Such expression was diminished by Lrp4 or MuSK mutation, revealing a necessary role of Lrp4 and MuSK in Lrp4 expression in the central region of muscle fibers. After NMJ formation, $\beta$-gal expression was in a good registry with AChR clusters, indicating NMJspecific activation of the Lrp4 promoter. Interestingly, the NMJ-specific $\beta$-gal expression in adult mice requires Lrp4, particularly the ECD and transmembrane domain of Lrp4 and neuronal activity. Finally, we showed that Lrp4 mRNA in C2C12 myotubes was increased by Wnt ligands, including Wnt3, Wnt3a, and Wnt5a. However, this effect was independent of the canonical pathway but was inhibited by RKI-1447, an inhibitor of non-canonical Wnt signaling [33, 34]. Injecting RKI-1447 into muscles of adult mice diminished Lrp4 synaptic expression. These results demonstrate that Wnt/ROCK non-canonical signaling increased the activity of Lrp4 promoter to promote mRNA expression. All together, synapse-specific Lrp4 mRNA enrichment requires Lrp4/MuSK signaling, muscle activity and may involve a Wnt non-canonical signaling pathway. We also posit that Lrp4-lacZ mice could serve as an informative mouse model to study synapsespecific mRNA enrichment.

\section{Result \\ Synapse-specific distribution of Lrp4 $\beta$-gal in Lrp4-lacZ mice}

Lrp4 protein is localized at the NMJ, and its mRNA is concentrated in the central region of muscle fibers $[5,8$, 28]. To study underlying mechanisms, we took advantage of Lrp4-lacZ mice where the Lrp4 gene was replaced with a cassette encoding a $\beta$-galactosidase ( $\beta$-gal) $[29$, $30]$. Under the control of the endogenous promoter, $\beta$-gal expression was expected to indicate where Lrp4 was expressed faithfully. Because two copies of the Lrp4 gene were replaced by the cassette in homozygous Lrp4lacZ/Lrp4-lacZ mice (referred to as lacZ/lacZ, unless otherwise specified), lacZ/lac $Z$ mice failed to form $A C h R$ clusters and NMJs and died soon after birth (data not shown). Heterozygous lac $Z /+$ mice were able to form AChR clusters at E13 and were viable and fertile as wildtype mice. Interestingly, $\beta$-gal activity in lac $Z /+$ mice was distributed in the central region of muscle fibers (Fig. 1a), in agreement with Lrp4 protein and mRNA enrichment at the NMJ $[5,8,28]$. To determine the $\beta$-gal activity was truly at the NMJ, we developed a method to sequentially imaging $A C h R$ and $\beta$-gal activity in the same muscle samples to avoid the quenching effect of $\beta$-gal staining on the AChR signal (see "Methods"). At E13, both AChR clusters and $\beta$-gal activity were enriched in the middle region of diaphragms, although the area of $\beta$-gal appeared to be larger than that occupied by AChR clusters (Fig. 1a, b). This may be because of $\beta$-gal diffusion 


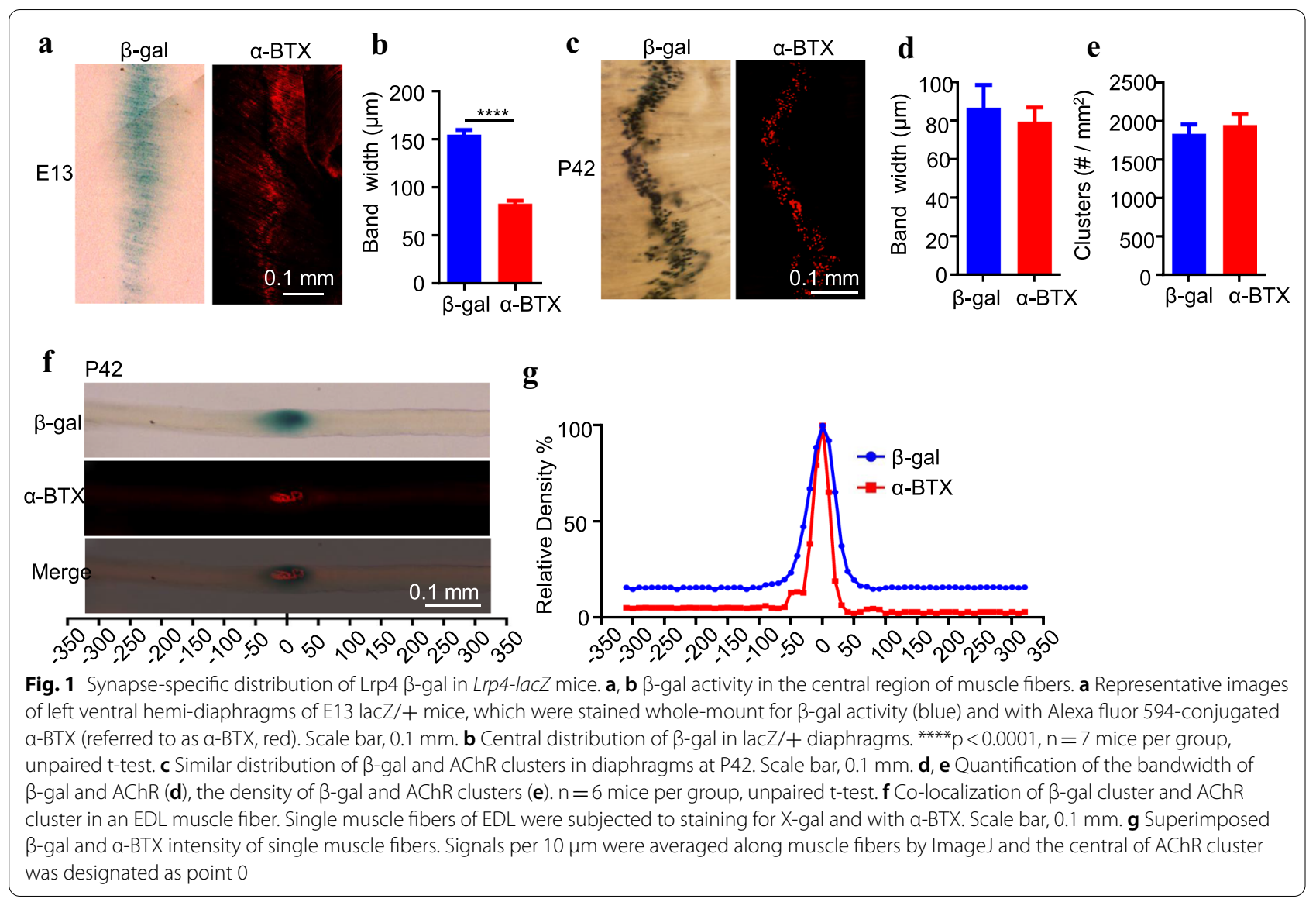

or poor innervation at this time and thus lack of muscle activity that may regulate synapse expression [31, 32]. Therefore, we examined $\beta$-gal in diaphragms of P42 mice. Interestingly, $\beta$-gal activity was distributed as aggregates, which colocalize with AChR clusters (Fig. 1c). The bandwidths and densities of $\beta$-gal clusters and AChR clusters were similar (Fig. 1d, e). To further confirm the co-localization of the $\beta$-gal cluster and AChR cluster, we assayed $\beta$-gal activity in individual muscle fibers and found it was present only at the NMJ (Fig. 1f, g). These results indicate that Lrp4 mRNA was concentrated at the NMJ and suggested that Lrp4 $\beta$-gal is a reliable indicator of the promoter activity of the $L r p 4$ gene $[8,28]$.

\section{Central localization of Lrp4 $\beta$-gal dependent on Lrp4/MuSK signaling}

To investigate mechanisms that regulate Lrp4 $\beta$-gal expression, we determined whether it required Lrp4/ MuSK signaling pathway. As shown in Fig. 2, in lacZ/+ mice, the $\beta$-gal activity was localized in the central region of muscle fibers. But, the central bandwidth of $\beta$-gal activity was increased in lacZ/lacZ mice, indicating a requirement of Lrp4 signaling for $\beta$-gal central localization. Similar, widened $\beta$-gal distribution was observed in MuSK-kd;lacZ/+ mice carried a kinase-dead MuSK (Additional file 1: Figure S1). And this was not due to the change of lacZ mRNA levels (Fig. 2c). These results suggested Lrp4/MuSK signaling is required for the concentration of Lrp4 mRNA at NMJ. To further test this hypothesis, we characterized diaphragms at P0 when AChR clusters are fully innervated in wild-type mice. At this time, $\beta$-gal activity was in the middle region of muscle fibers in lacZ/+ mice but completely diffused in lacZ/ lac $Z$ mice (Fig. 3a-d), again indicating the requirement of Lrp4. This phenotype was diminished after $l a c Z /+$ mice were crossed with HSA-Lrp4 mice that express wild type Lrp4 under the control of the HSA promoter [35]. This was not due to a change in lacZ mRNA levels (Fig. 3e). Together, these results indicate that synaptic distribution of Lrp4 mRNA required Lrp4 and associated signaling in the NMJ development.

\section{A critical role of the transmembrane domain of Lrp4 for synaptic localization of Lrp4 $\beta$-gal}

Lrp4 is a transmembrane protein with a large multidomain ECD that interacts with agrin and MuSK. In vitro experiments showed that Lrp4 ECD was sufficient to enable agrin to activate MuSK in HEK293 cells, 

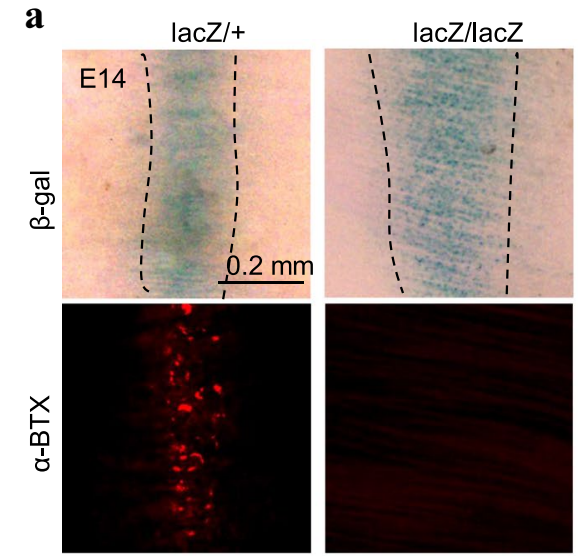
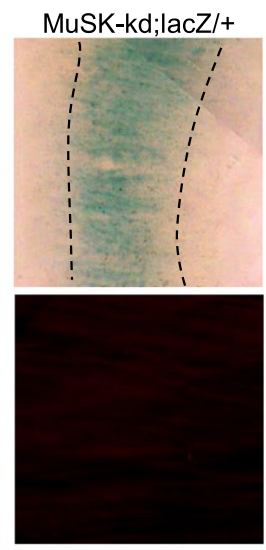

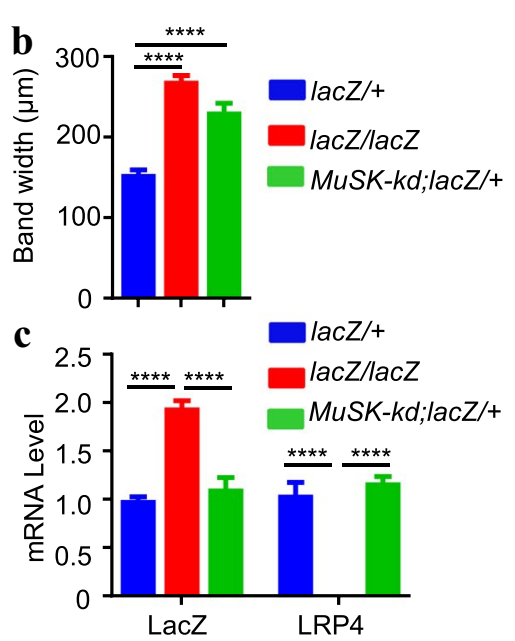

Fig. 2 Requirement of Lrp4/MuSK signaling for central region localization of Lrp4 $\beta$-gal in mouse embryos. Diaphragms were isolated from E14 embryos of indicated genotypes. a Representative images. The increased bandwidth of Lrp4 $\beta$-gal in lacZ/lacZ and MuSK-kd;lacZ/+ mice. b Quantitative analysis of Lrp4 $\beta$-gal bandwidth. c The mRNA levels of lacZ and Lrp4 in lacZ/lacZ and MuSK-kd;lacZ/+ mice. The transcription activity of the Lrp4 promoter didn't require Lrp4 and MuSK in vivo. Data were shown as mean $\pm S E M,{ }^{* * *} p<0.0001, n \geq 6$ per group, one-way ANOVA

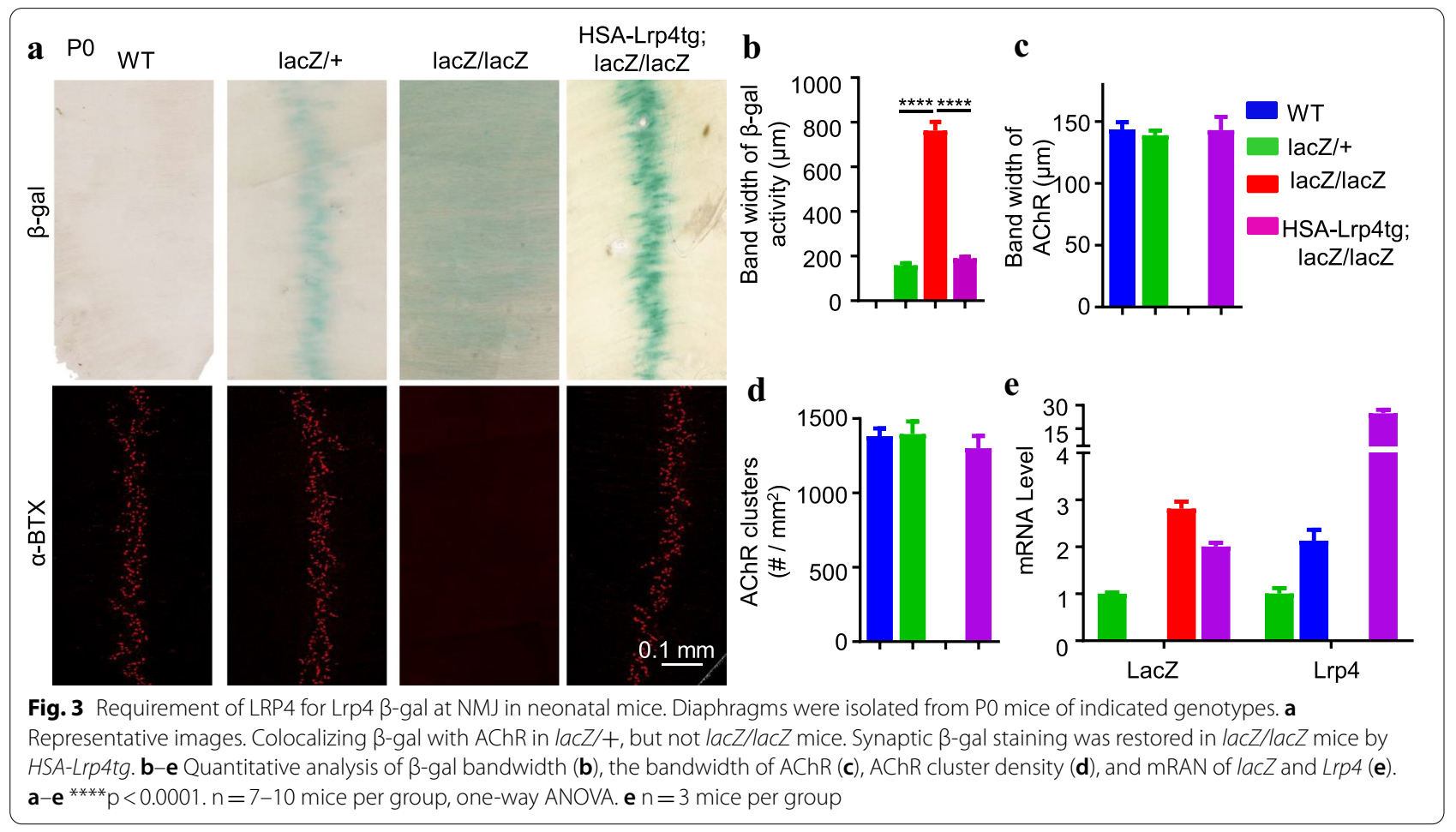

suggesting soluble ECD could function as a receptor $[27,36,37]$. To investigate how Lrp4 signaling regulates $\beta$-gal central localization, we crossed lacZ/+ mice with ECD mutant mice that express LRP4 ECD but without the transmembrane domain and ICD [26]. The resulting compound lacZ/ECD mice carried one copy $E C D$ and one copy lacZ. Compared with lacZ/lacZ mice at
P0, the bandwidth of the $\beta$-gal activity in lacZ/ECD mice was narrower (Fig. 4a, b). Concomitantly, AChR clusters were barely detectable in lacZ/lacZ mice but readily detectable in lacZ/ECD mice (Fig. $4 \mathrm{a}-\mathrm{c}$ ). However, compared with lacZ/+ mice that express one copy of wild type LRP4, the $\beta$-gal activity of lacZ/ECD distributed in a wider region, and the number of $A C h R$ clusters 


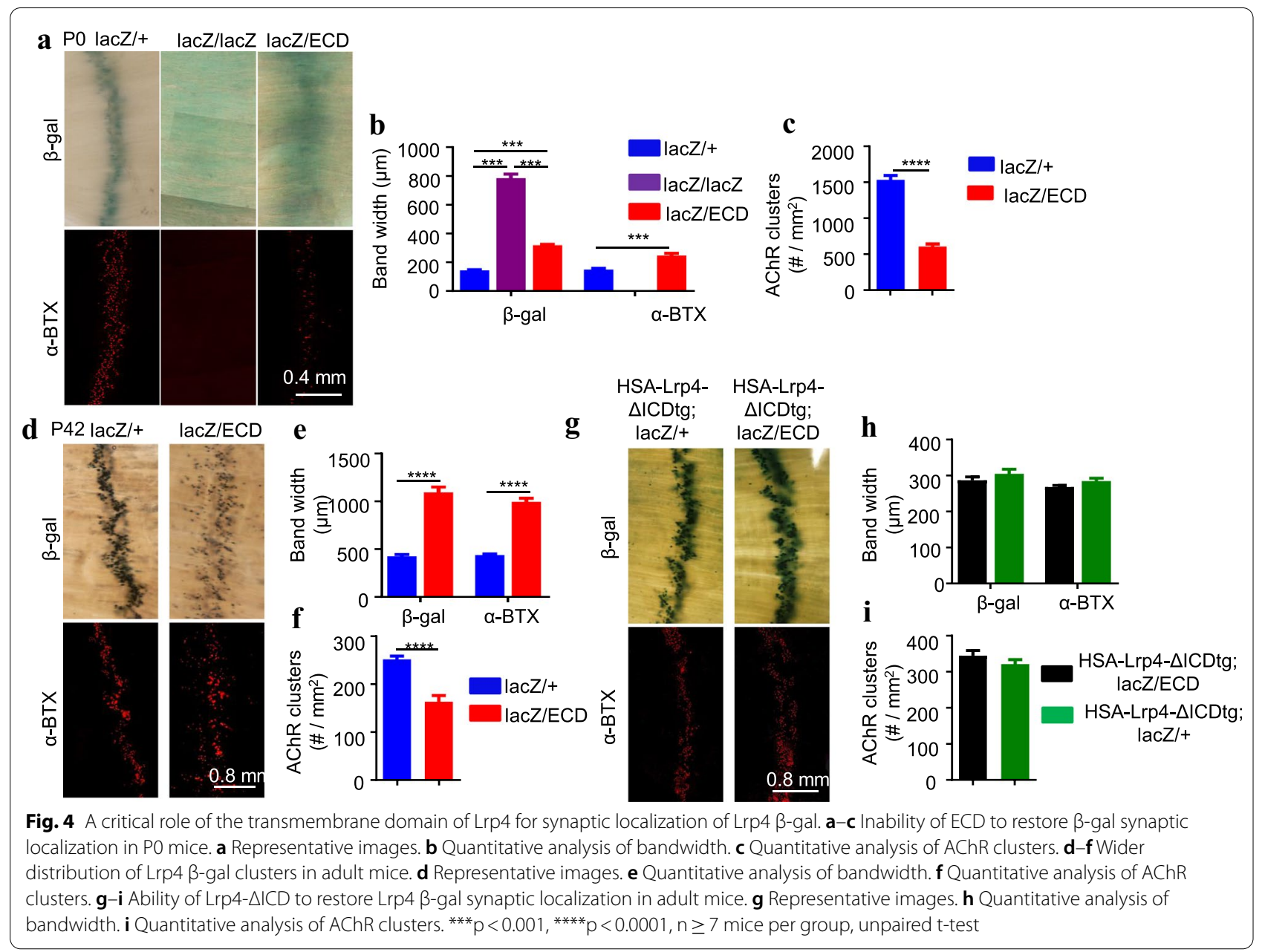

was much fewer (Fig. $4 \mathrm{a}-\mathrm{c}$ ). These results suggest that ECD partially rescued NMJ deficits and widened $\beta$-gal distribution by LRP4 mutation. At P42, the distribution of $\beta$-gal and AChR clusters was wider, and the cluster number smaller in lacZ/ECD mice than in lacZ/+ mice (Fig. 4d-f). These results suggest that full Lrp4 signaling cannot be mediated by ECD alone but requires the transmembrane domain. To test this hypothesis, we generated HSA-Lrp 4 $\triangle I C D$ mice that express Lrp4 ECD and transmembrane domain (but without ICD). As shown in Fig. 4g, transgenic expression of Lrp4 $\triangle I C D$ was able to rescue the $\beta$-gal distribution phenotype in lacZ/ECD mice (Fig. $4 \mathrm{~g}-\mathrm{i}$ ). These results suggest that the synaptic distribution of $\beta$-gal requires the signaling mediated by the ECD and transmembrane domain of Lrp4.

\section{Requirement of muscle activity for Lrp4 $\beta$-gal distribution at NMJs}

Synaptic expression at the NMJ requires neuronal activity, which via releasing ACh controls muscle activity $[38,39]$. For example, AChR expression is suppressed by muscle electric activity [40]. To determine whether Lrp4 mRNA synaptic distribution is regulated by neuronal activity, we studied the effect of denervation. As shown in Fig. $5 a, \beta$-gal activity was confined to the middle of muscle fibers of TA muscles in control mice but gradually diffused after denervation at day 3 after denervation. The $\beta$-gal activity was not detectable by staining in muscles at day 5 and afterward. This reduction was not due to the reduced level of lacZ mRNA, which was in fact increased in denervated muscles of lacZ/+ mice beginning at day 3 (Fig. $5 \mathrm{~b}$ ). In particular, lac $Z$ mRNA peaked at day 3 when $\beta$-gal activity at the NMJ began to reduce. In addition, denervation didn't affect synaptic nuclei aggregation (Additional file 1: Figure S2). These results suggest that muscle activity could suppress the Lrp4 promoter activity but is required for synaptic Lrp4 mRNA. To further test this hypothesis, we studied the effect of $\mu$-conotoxin, a toxin that inhibits muscle activity by blocking muscle-specific voltage-gated sodium channels [41]. The TA muscles of adult lacZ/+ mice were injected with $\mu$-conotoxin 


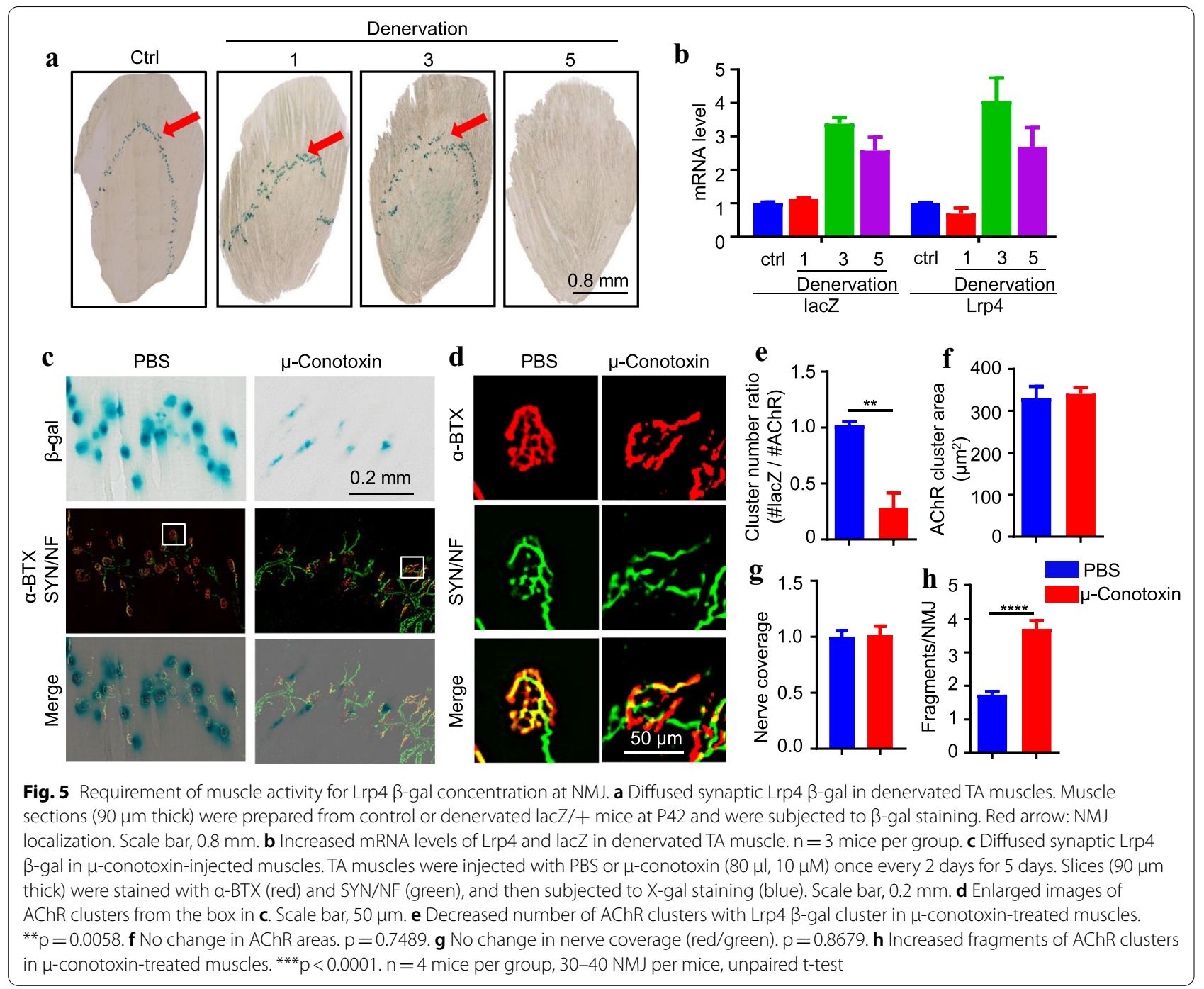

(80 $\mu \mathrm{l}, 5 \mu \mathrm{M}$ for twice, at 1st day and 3rd day), where control muscles were injected with PBS. In $\mu$-conotoxin treated TA muscle, the CMAP amplitude of 1 st stimulation decreased, and muscle tetanic force decreased by electrical-stimulated muscle, but the CAMP amplitude ratio of 1st/10th was not changed compared with the control group (Additional file 1: Figure S3). These indicate $\mu$-conotoxin blocks muscle excitability but does not affect synapse transmission. However, $\beta$-gal activity at the NMJ was dramatically reduced in TA muscles of toxin injected lac $/+$ mice (Fig. $5 \mathrm{c}$ ). The number of $\beta$-gal clusters, but not AChR clusters, was reduced, leaving many AChR clusters without $\beta$-gal staining (Fig. 5c, e). Notice that $\mu$-conotoxin did not affect the size of AChR clusters (Fig. 5f) and their innervation (Fig. 5g). Nevertheless, in toxin injected lacZ/+ mice, AChR clusters appeared to be more fragmented (Fig. 5h). Together, these results are in agreement with the notion that $\beta$-gal synaptic distribution requires muscle activity.

We also studied the effect of aging on Lrp4 $\beta$-gal expression in aged mice because aging is associated with a NMJ decline [3]. As shown in Fig. 6, the $\beta$-gal activity was detected only at NMJ at 6 months (M) of age. At $18 \mathrm{M}$, the $\beta$-gal activity became detectable in regions outside of the NMJ. At $27 \mathrm{M}$, the $\beta$-gal activity was diffused and detected in the non-synaptic region (Fig. 6b-d). This is associated with an increase in mRNA (Fig. 6e). To determine this was due to reduced muscle activity, we stimulated TA muscles of $26 \mathrm{M}$-old mice with electricity $(100 \mathrm{~mA}, 0.2 \mathrm{~ms}, 1 \mathrm{~s}, 5 \mathrm{~Hz} \times 50$ times per day) for 30 days. Remarkably, the $\beta$-gal activity in the non-synaptic region was decreased but increased in NMJ (Fig. 6d). These results indicate Lrp4 $\beta$-gal synaptic enrichment requires muscle activity. 


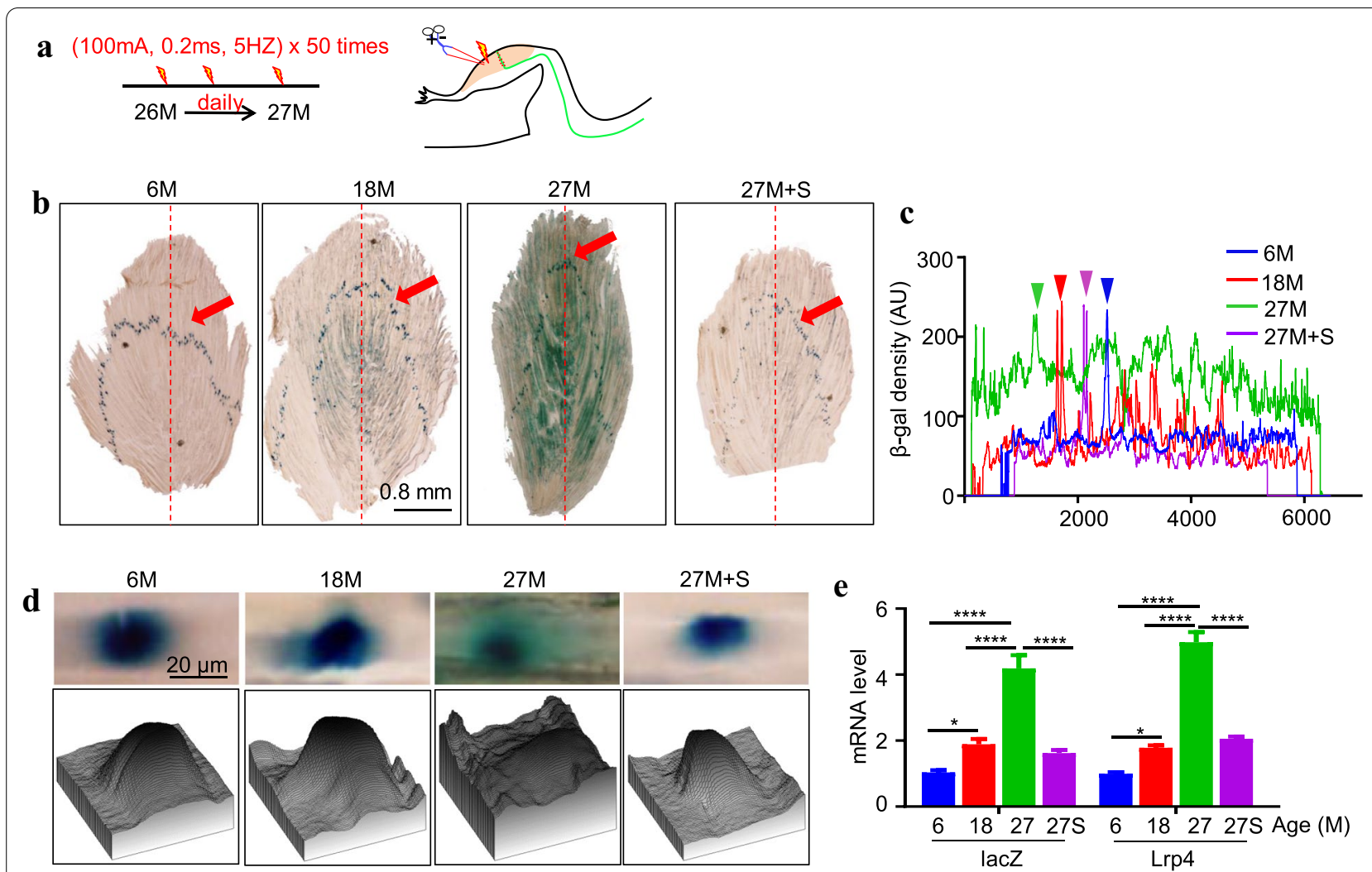

Fig. 6 A necessary role of muscle activity for Lrp4 $\beta$-gal synaptic localization in aged mice. a Scheme of electric stimulation of muscle. $\mathbf{b} L$ Lrp4 $\beta$-gal was diffused in aged muscles but became localized at NMJ after electric stimulation of muscle. Red arrow: NMJ localization. Scale bar, $0.8 \mathrm{~mm}$. c Quantification of Lrp4 $\beta$-gal across muscle fibers (the red dotted line of $\mathbf{b}$ ). Triangle indicates NMJ localization. $\mathbf{d}$ Synaptic Lrp4 $\beta$-gal distribution revealed by surface plot analysis. Scale bar, $20 \mu \mathrm{m}$. e Increased mRNA of lacZ and Lrp4 in aged muscles but reduced by stimulation. ${ }^{*} \mathrm{p}<0.05$ ${ }^{*}$ lacZ $=0.019,{ }^{*}$ Lrp4 $\left.=0.0398\right),{ }^{* * *} p<0.0001 . n=4$ mice per group, one-way ANOVA. M: month; S: stimulation; $27 \mathrm{~S}: 27 \mathrm{M}+\mathrm{S}$

\section{Wnt promotion of Lrp4 expression by a non-canonical pathway}

To understand regulatory mechanisms of Lrp4 expression, we screened for factors that could enhance mRNA levels of $\operatorname{Lrp} 4$ in muscle cells. We focused on factors that have been implicated in NMJ formation. Noticeably, Lrp4 mRNA levels were increased by several Wnt ligands, including Wnt3, Wnt5a, Wnt9a, and Wnt10a (Fig. 7a). This effect appeared to be specific because Lrp4 mRNA levels were not enhanced by neuregulin 1 (Nrg1), Bdnf, Ngf, Gabp-a, Gabp- $\beta 1$, MyoD, Myf5, ERK, PI3K, MEK, AKT, and PAK1 pathway (Fig. 7a). In addition, Wnt3 did not affect mRNA levels of MuSK, Dok7, rapsyn, AChR $\gamma$, and AChRe (Fig. 7b). Moreover, Lrp4 mRNA was also not increased by neuron agrin stimulation or the expression of MuSK or the kinase-dead mutant K608A (Fig. 7c). These results suggest that Wnt ligands could increase lrp4 expression. To determine which intracellular pathways are required, we first overexpressed proteins known to regulate the $\beta$-catenin signaling, including Axin 1 , GSK-3B-KM (a kinase-deficient mutant), or $\beta$-catenin in
C2C12 myotubes. We found Lrp4 mRNA was not altered by their expression (Fig. 8a), suggesting Lrp 4 expression may not be regulated by the canonical pathway. Next, we treated C2C12 myotubes with RKI-1447, an inhibitor of ROCK $1 / 2$, implicated in the Wnt non-canonical pathway [42-44]. It dose-dependently reduced Lrp4 mRNA levels (Fig. 8b). As a control, RKI-1447 did not affect mRNA or protein levels of MuSK (Fig. 8c, d). Finally, RKI-1447 was able to inhibit the Wnt3-stimulated expression of Lrp4 (Fig. 8e). These results demonstrate that Lrp4 expression is regulated by Wnt signaling, possibly via the noncanonical pathway.

\section{Disruption of Lrp4 $\beta$-gal synaptic expression by RKI-1447}

To determine whether the non-canonical pathway contributes to Lrp4 synaptic expression in vivo, RKI-1447 (80 $\mu \mathrm{l}, 10 \mu \mathrm{M}$ for twice, 1st day and 3rd day) into TA muscles of adult lac $Z /+$ mice for 5 days. Contralateral TA muscles were injected same volumes of vehicle $(5 \%$ DMSO) as control. Five days after injection, TA muscles were first co-stained with Alexa Fluor ${ }^{\mathrm{TM}}$ 594-conjugated 


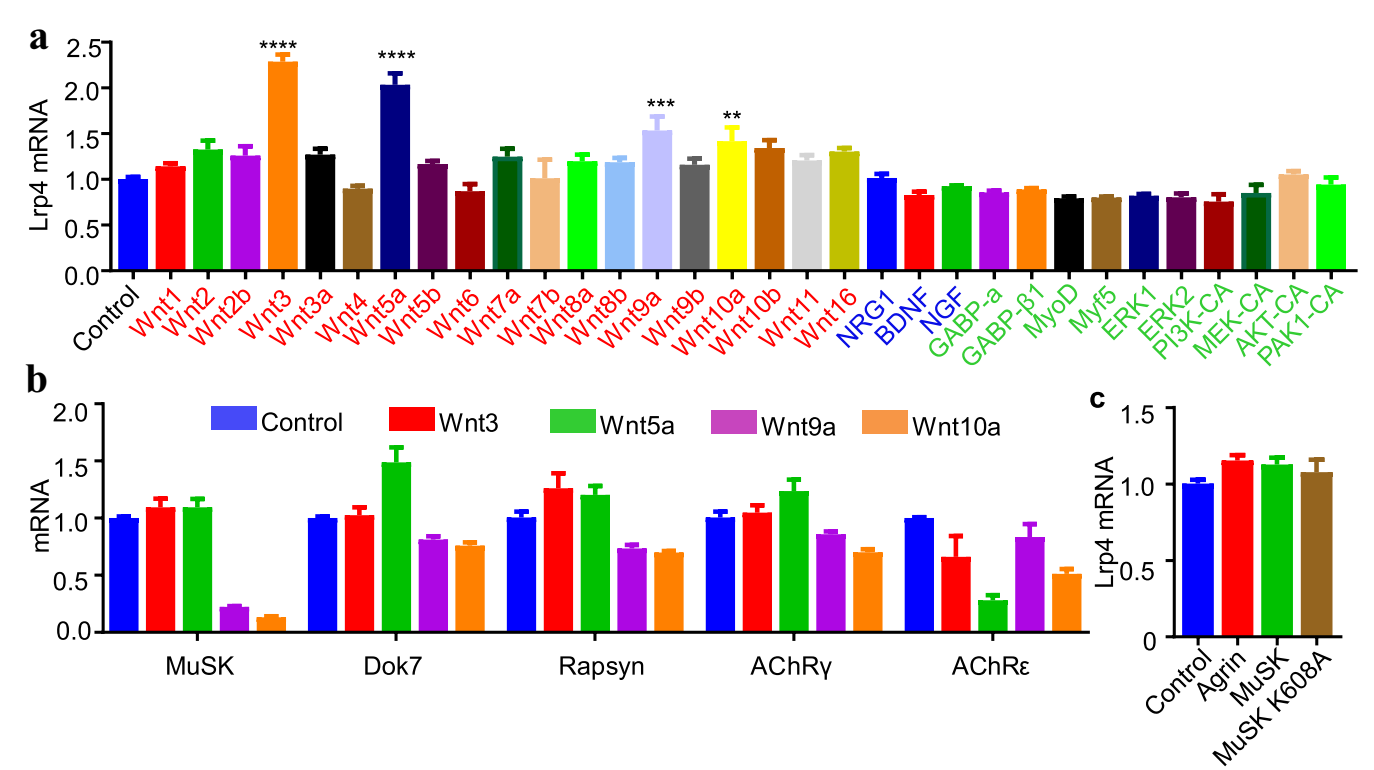

Fig. 7 Increased Lrp4 mRNA expression by Wnt ligands. C2C12 myoblasts were transfected with plasmids. The resulting myotubes were subjected to qRT-PCR. a Lrp4 mRNA increased by Wnt3, wnt3a, wnt5a, wnt9a, and wnt10a. b Effects of Wnt ligands on MuSK, Dok7, rapsyn, and AChRY- and $\varepsilon$-subunits. $\mathbf{c}$ No effect of agrin or MuSK or its mutant on LRP4 expression. ${ }^{* *} p=0.0038^{* * *} p=0.001,{ }^{* * *} p<0.0001, n \geq 4$, one-way ANOVA
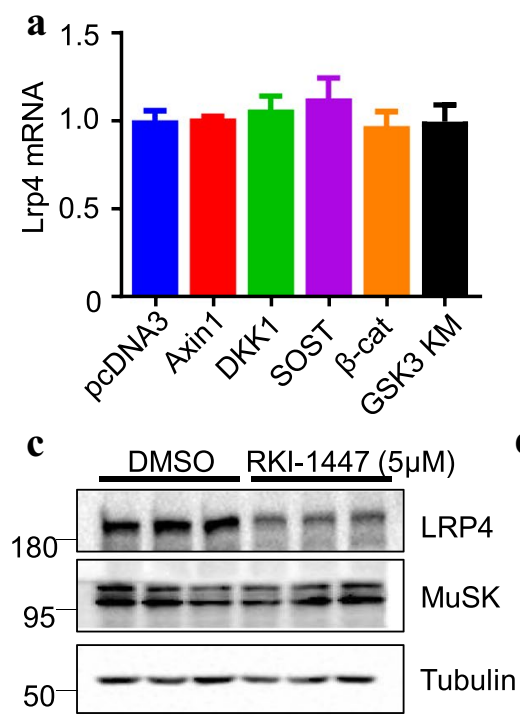
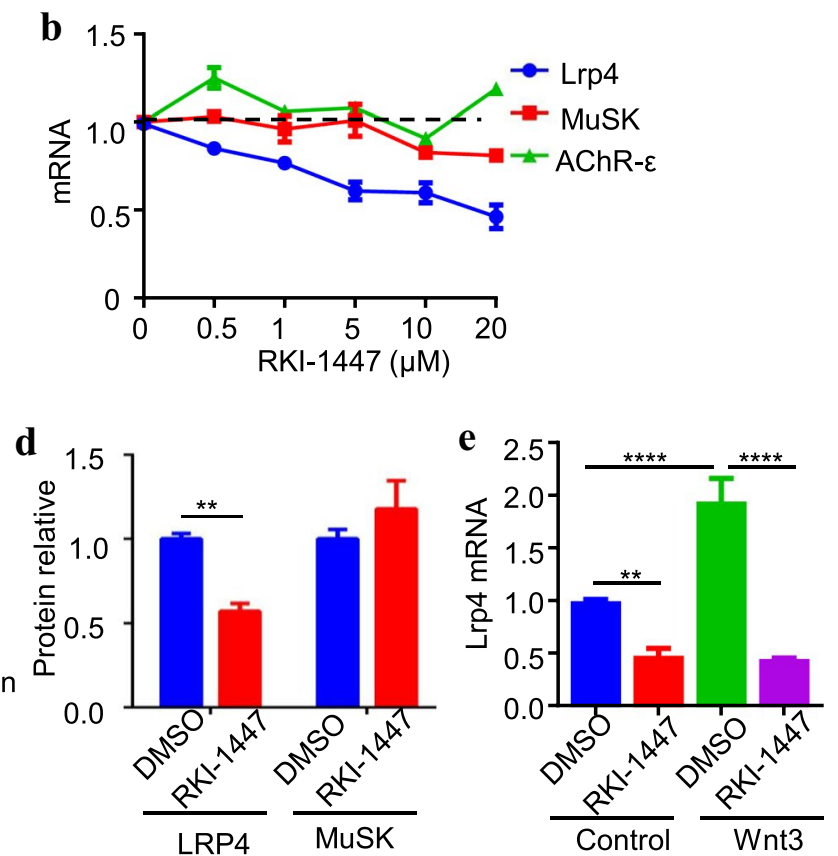

Fig. 8 Inhibition of Lrp4 expression by ROCK inhibitor RKI-1447. a No effect of canonical Wnt signaling molecules on Lrp4 mRNA levels. $\mathrm{n}>4$, one-way ANOVA. $\mathbf{b}$ Reduced Lrp4 mRNA by RKI-1447. Myotubes were treated with RKI-1447 for $8 \mathrm{~h} . \mathrm{n}>3$. $\mathbf{c}$, d Reduced Lrp4 protein in RKI-1447-treated C2C12 myotubes. c Representative blots. $\mathbf{d}$ Quantification of data in $\mathbf{c}$. ${ }^{* *} p=0.0016, n=3$, unpaired t-test. e Inhibition of Lrp4 expression in Wnt3-expressing C2C12 myotubes. ${ }^{* *} p=0.0047$, ${ }^{* * *} p<0.0001, n \geq 6$, one-way ANOVA 
$\alpha-B T X$ and antibodies against SYN/NF and then stained for $\beta$-gal activity (see "Methods"). As shown in Fig. 9, RKI-1447 did not affect the fragments (Fig. 9a-c), size of AChR clusters (Fig. 9b, d) or their innervation (Fig. 9b, e). However, $\beta$-gal activity was dramatically decreased in RKI-1447-injected TA muscles compared with control. Many AChR clusters were left without $\beta$-gal activity (Fig. 9a, f), indicating that Lrp4 synaptic expression requires the non-canonical pathway of Wnt signaling.

\section{Discussion}

By studying the $\beta$-gal expression of Lrp4 lacZ mice, we demonstrate that synaptic specific Lrp4 mRNA enrichment requires the Lrp4/MuSK signaling, muscle activity, and Wnt non-canonical signaling. In brief, Lrp4/ MuSK signaling and muscle activity are responsible for the localization of Lrp4 mRNA, and Wnt non-canonical signaling promotes Lrp4 mRNA expression.

This study, we use $\beta$-gal activity to indicate the Lrp4 mRNA in Lrp4-lacZ mice where the Lrp4 gene was replaced with the lac $Z$ gene. First, under the control of the endogenous promoter, $\beta$-gal expression indicated Lrp4 mRNA expression. This has been reported in a previous paper [30]. Secondary, in E14 and P0 lacZ/+ mice, the distribution of $\beta$-gal activity in the diaphragm was consistent with the previously reported result of Lrp4 mRNA in situ hybridizations (Figs. 2a, 3a) [8]. Finally, in diaphragms of $\mathrm{PO}$ lacZ/lacZ mice or denervated TA muscle of adult lacZ/+ mice (Figs. 3a, 5a), the mRNA level of lacZ didn't decrease, but the $\beta$-gal cluster was diffused. And in AChR $\alpha$-nlacZ transgenic mice, min $A C h R \alpha$ promoter-driven nls-lac $Z$ was detected in all muscle nuclei [45]. These results suggest the localization $\beta$-gal in

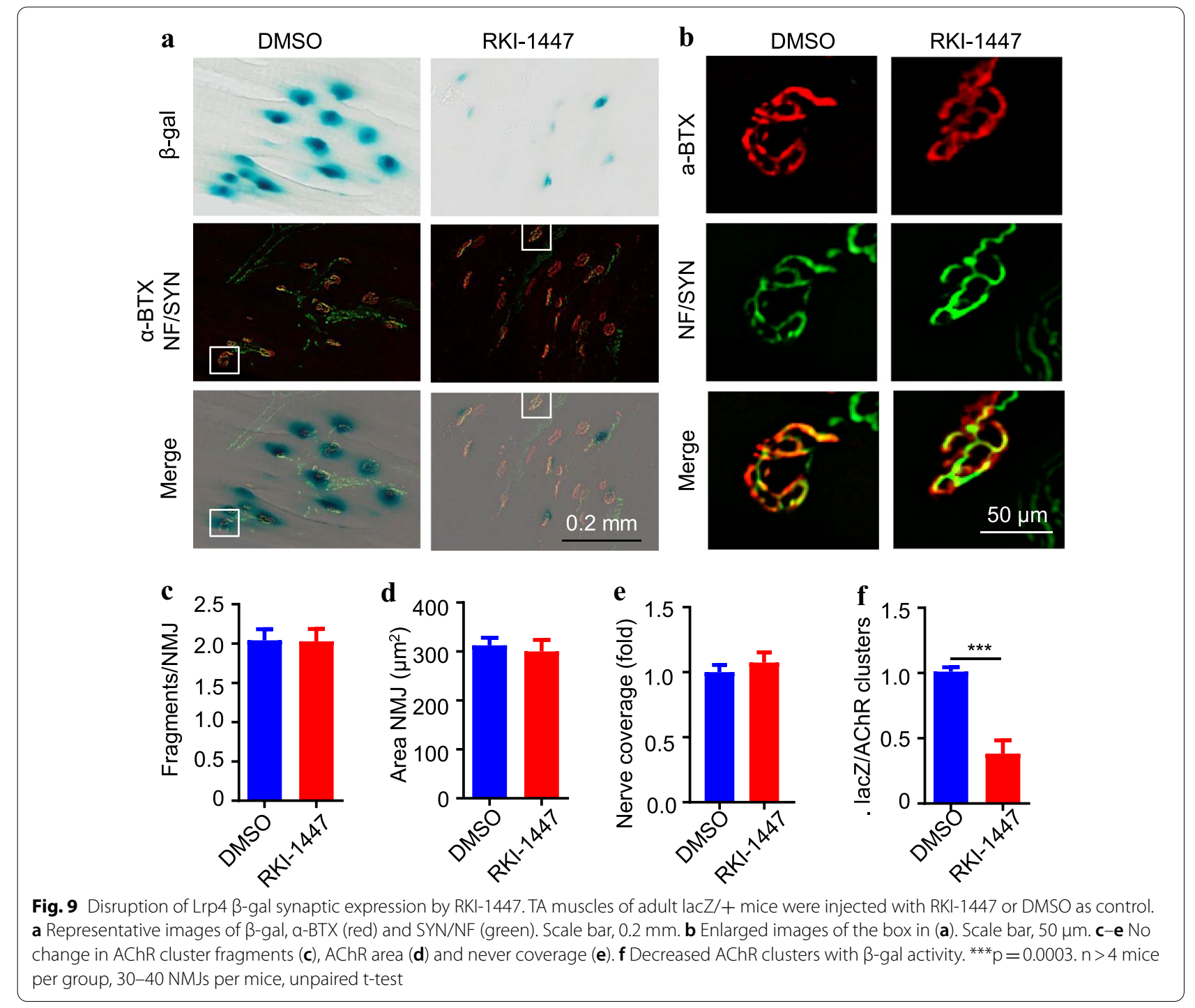


lacZ $/+$ mice is determined by the promoter or $5^{\prime}$ UTR of the Lrp4 gene, not due to the characteristics of the $\beta$-gal protein. And these also indicate $\beta$-gal was able to faithfully indicate the expression and localization of Lrp4 mRNA in Lrp4-lacZ mice.

Lrp4 is a transmembrane protein with a huge ECD containing an LDLa domain and four $\beta$-propeller domains. Agrin binds to the $\beta 1$ domain to form a binary complex, two of which form a tetramer (i.e., two agrin and two Lrp4) to activate MuSK [4-6]. The tetrameric complex is essential for MuSK activation [4], likely by promoting the interaction with MuSK (via LRP4's $\beta 3$ domain) $[5,6]$. Interestingly, soluble ECD of Lrp4 is sufficient to serve as agrin's receptor to stimulate MuSK $[27,36]$. Likewise, genetic rescue experiments show that NMJ deficits of Lrp4 null mice could be diminished by transgenic expression of a mutant Lrp4 without the intracellular domain (ICD) [26, 35]. These results suggest that the ICD of Lrp4 is unnecessary for agrin signaling, although it contains a characteristic NPXY motif $[3,46]$. In agreement, mutant mice that express the Lrp4 ECD (i.e., LRP4 without the transmembrane domain and ICD) could survive to five months, unlike null mice that die soon after birth [26]. NMJ formation is retarded in ECD/ECD mice, with $\mathrm{AChR}$ clusters distributed across a broader region of muscle fibers, prolonged nerve branches, and smaller AChR clusters [26]. We show that the $\beta$-gal activity in lac $Z /+$ mice was localized in the central region in mouse embryos and at the NMJ in adult mice (Fig. 1). However, the $\beta$-gal activity was diffused in lacZ/lac $Z$ mice before and after innervation (although with increased $\beta$-gal mRNA level), indicating that Lrp4 is required for the central localization of Lrp4 (Figs. 2 and 5). This phenotype was rescued in Lrp4 $\triangle I C D$ tg mice, suggesting that the ICD is dispensable (Fig. 4). Interestingly, synaptic $\beta$-gal expression was not fully rescued by ECD expression; the bandwidth of $\beta$-gal and AChR remained larger in lacZ/ $E C D$ than $l a c Z /+$ mice. These results indicate that the transmembrane domain of Lrp4 is critical to synapsespecific transcription.

Synapse-specific transcription is regulated by muscle activity. Reducing muscle activation by denervation, for example, increases the level of NMJ-specific mRNAs in non-synapse regions $[13,14,40]$. A current model of synapse-specific transcription is that muscle activation, in response to nerve stimulation, suppresses the gene expression in entire muscle fibers. However, gene expression is maintained at the NMJ because of local activation of the agrin-Lrp4-MuSK signaling [3, 38, 47]. We found that Lrp4 $\beta$-gal was increased at the NMJ 1 and 3 days after denervation (Fig. $5 \mathrm{a}$ ) but became undetectable at the NMJ 5 days after denervation, although both Lrp4 mRNA and lacZ mRNA were increased (Fig. 5b).
This result suggests that muscle activity may play an active role in synapse-specific transcription. This notion is supported by data from experiments with $\mu$-conotoxin, which reduced $\beta$-gal activity at the NMJ (Fig. 5c) but didn't affect the transmission of NMJ (Additional file 1: Figure S3). This also suggests agrin-Lrp4-MuSK signaling doesn't regulate Lrp4 gene expression, which is consistent with the results of changing the MuSK activity in C2C12 (Fig. 7c). In addition, in aged (27 mo) mice, LRP4 $\beta$-gal was diffused into entire muscle fibers, and NMJ localization became murky (Fig. 6). Remarkably, in vivo muscle stimulation restored $\beta$-gal NMJ localization. These results demonstrate that muscle activity may play an active role in regulating NMJ-specific Lrp4 mRNA enrichment. And they also suggest that reduced synapsespecific Lrp4 mRNA enrichment in aging may benefit by increasing muscle activity or exercise.

Wnt signaling has been implicated in NMJ formation [3, 38, 48, 49]. Wnt ligands can induce AChR clusters and potentiate agrin-induced formation of $\mathrm{AChR}$ clusters in cultured muscle cells $[48,49]$. These effects seem to require the cysteine-rich domain (CRD) of MuSK, whose deletion impairs in vivo NMJ formation $[4,50$ 53], although this notion was challenged by another study [54]. MuSK interacts with disheveled (Dvl1), the critical scaffold protein in the Wnt signal pathway [55]. This interaction is required for forming the NMJ in vitro [55] and for axon guidance to the middle region of muscle fibers [53]. Mutant mice lacking or overexpressing $\beta$-catenin, a key mediator of the Wnt canonical pathway, in muscle fibers display both pre-and postsynaptic deficits [56-58]. Motoneuron-specific mutation of Wls, a protein necessary for Wnt cell surface [59], reduces synaptic junctional folds, increases $\mathrm{AChR}$ cluster fragments, and impairs presynaptic nerve terminals [60]. This study provides evidence that Wnt signaling contributes to synapse-specific localization of Lrp4 $\beta$-gal. First, Wnt ligands including Wnt3, Wnt5a, Wnt9a, and Wnt10a increase Lrp4 mRNA in cultured muscle cells (Fig. 7a). Second, Lrp4 mRNA was not altered by expressing regulators of Wnt canonical signaling such as $\beta$-catenin (Fig. 8a). Third, however, Lrp4 mRNA, either basal or Wnt3induced, was reduced in muscle cells treated with RKI1447, an inhibitor of the non-canonical ROCK pathway (Fig. 8e). Finally, Injecting RKI-1447 into muscles of adult mice diminished LRP4 synaptic expression (Fig. 9a). These results indicate Wnts promote Lrp4 expression via the non-canonical ROCK pathway.

In NMJ, some protein concentrations are due to the mRNA enrichment, like Lrp4, MuSK, AChR $\alpha, A C h R \delta$, $\mathrm{AChR \varepsilon}$, etc. But the mechanism is not all the same [61]. For mRNA expression, $A C h R \varepsilon$ is only expressed in synaptic nuclei, but Lrp4, MuSK, AChR $\alpha$ are expressed in 
synaptic nuclei and non-synaptic nuclei [45, 62]. Agrin increases $A C h R \varepsilon$ expression but does not affect other NMJ critical genes [22]. GABP $\alpha / \beta$ regulated $A C h R \delta$ and Utrophin mRNA expression [63, 64]. But our data show it didn't affect Lrp4 mRNA expression. In our study, Wnt3 promotes Lrp4 expression. This effect was specific because Wnt3 did not affect mRNA levels of MuSK, Dok7, rapsyn, AChRy and $\varepsilon$ (Fig. 7b). And blocking ROCK with RKI-1447 decreased Lrp4 expression in C2C12 myotubes, but does not affect MuSK and AChR $\varepsilon$ (Fig. 8b). For mRNA localization, the mRNA distribution of MuSK, AChR $\alpha$ and $\delta$ was diffused in LRP4 mutant mice [8]. This phenotype is similar to the $\beta$-gal distribution in lacZ/lacZ mice (Figs. 2a, 3a). This indicated synapse-specific mRNA enrichment of MuSK, AChR $\alpha$ and $\delta$ required Lrp4 signaling. Here, we demonstrated the evidence of synapse-specific Lrp4 mRNA enrichment. LRP4/MuSK signaling regulated NMJ formation and maintenance to control muscle activity through NMJ. And then, muscle activity regulated Lrp4 mRNA enrichment in NMJ. This mechanism may also apply to the localization of NMJ other gene mRNAs.

\section{Conclusions}

We report that synaptic-specific enrichment of Lrp4 requires the Lrp4/MuSK signaling, muscle activity, and Wnt non-canonical signaling. The role of muscle activity in regulating NMJ-specific mRNA enrichment suggests that reduced synapse-specific mRNA enrichment in aging may benefit by increasing muscle activity or exercise. Thus, it provides a potential treatment of NMJ aging and other NMJ-related diseases.

\section{Methods}

\section{Mouse strains}

LRP4 ECD, HSA::LRP4-FL $L^{T g}$, and HSA::LRP4- $\triangle I C D^{T g}$ were described previously $[26,35]$. The following mice were described previously $L R P 4-L a c Z$ with genotyping primers being: 5'-TTC TGC CCA GGA ATA GCC AG-3' and 5'-TGA GCG AGT AAC AAC CCG TC-3' (KOMP, stock \#VG15248) [30], LRP4-ECD with genotyping primers being: 5'-CTC CAA TTT CCT GTC CCT TG-3', 5'-GCC AGA GGC CAC TTG TGT AG-3' and 5'-CTG CAG CAG AGC TGA GGT TA-3' [26], HSA::LRP4$\triangle I C D^{T g}$ and HSA::LRP4-FL ${ }^{T g}$ [35]. MuSK-K608A (MuSK$k d)$ mice were generated by CRISPR-Cas9 and contain a K608A mutation-Lys608 (K608) to Analine (A), with genotyping primers being: $5^{\prime}$-CAG GCT AAC CAG TAG GAG GTT ACA-3 and 5'-GAG AGG AAG AGA CAT ATC GCA CTG-3' and sequencing the PCR products to identify the genotype. HSA::LRP4-FL ${ }^{T g}$ mice (LRP4FLtg) expressed Flag-LRP4 in muscles under the control of the promoter of human skeletal a-actin (HSA) with genotyping primers being: 5'-AAG AAA GAG GGT GGA CCT GAC-3 and 5'-ACT GCT TCC TTC ACG ACA TTC-3'. HSA::LRP4- $\triangle I C D^{T g}$ mice (LRP4- $\triangle I C D t g$ ) expressed Flag-LRP4 without the intracellular domain under the control of the HSA promoter, with genotyping primers being: 5'-TGC CCA CCA CCT TAC ATT CT-3' and 5'-GAA CTG CTT CCT TCA CGA CAT-3'. Mice were housed in a room with a 12-h light/dark cycle with ad libitum access to water and rodent chow diet.

\section{Chemicals}

Chemicals and reagents were purchased from the following companies: 5-bromo-4-chloro-3-indoly $\beta$-Dgalactopyranoside ( $\beta$-gal, B4252) from Sigma-Aldrich (Poole, UK); RKI-1447 (S7195) from Selleckchem (Houston, TX, USA) and Alexa Fluor ${ }^{\mathrm{TM}}$ 594-conjugated $\alpha$-BTX (\#B13423，1:3000 for staining) from Thermo Fisher (Lafayette, Colorado, USA). Information of antibodies was as follows: synapsin (D12G5, 1:1000 for staining); neurofilament (Millipore, AB1991; 1:1000 for staining); LRP4 (ECD) clone N207/27 (UC Davis/NIH NeuroMab Facility; \#75-221, 1:500 for western blotting) [27, 29, 30, 65]; LRP4(ICD) clone N164/6 (UC Davis/NIH NeuroMab Facility; \#73-182, 1:500 for western blotting); MuSK (1:1000 for western blotting) [5]; $\alpha$-tubulin (Santa Cruz Biotechnology, sc-23948, 1:2000 for western blotting); Alexa Fluor 488-conjugated goat anti-rabbit IgG (Invitrogen, A-11034, 1:1000 for staining); horseradish peroxidase (HRP)-conjugated goat anti-rabbit IgG (Invitrogen, 31460, 1:2000 for western blotting) and goat anti-mouse IgG (Invitrogen, 31430, 1:2000 for western blotting) secondary antibodies.

Constructs expressing Flag-tagged Agrin, MuSK, LRP4, Wnt2, Wnt2b, Wnt3, Wnt3a, Wnt5a, Wnt5b, Wnt7a, Wnt8a, Wnt8b, Wnt9a, Wnt9b, Wnt10, Wnt10b, Wnt11 and Wnt16 were described previously [60, 66]. Constructs expressing HA-tagged Wnt1, Wnt4, Wnt6 and Wnt7b were generously provided by Dr. Xi He [60].

\section{Immunohistochemistry (IHC)}

Diaphragms were dissected out and fixed with $4 \%$ paraformaldehyde (PFA) for $20 \mathrm{~min}$ at $4{ }^{\circ} \mathrm{C}$. After washing with phosphate-buffered saline (PBS) 3 times each for $30 \mathrm{~min}$ at room temperature (RT), diaphragms were treated with $0.1 \mathrm{M}$ glycine for $1 \mathrm{~h}$ at $\mathrm{RT}$ and washed 3 times with PBS containing $0.5 \%$ Triton X-100, each for $30 \mathrm{~min}$ at RT. After incubating with the blocking buffer containing $5 \%$ goat serum, $2 \%$ BSA, $0.2 \%$ Triton X-100, $0.1 \%$ NaN3 in PBS, pH 7.4 for $3-4$ h at RT or overnight at $4{ }^{\circ} \mathrm{C}$, samples were incubated with primary antibodies in the blocking buffer for $24 \mathrm{~h}$ at $4{ }^{\circ} \mathrm{C}$. Then samples were washed with PBS containing 0.5\% Triton X-100 3 times, each for $30 \mathrm{~min}$ at RT, and mounted on gelatin-coated 
slides with Hydromount (National Diagnostics, HS-106). Z serial images were collected with an Olympus FSX100 fluorescence microscope (Olympus, Tokyo, Japan).

\section{X-gal staining}

The anterior tibialis muscle was fixed in 4\% PFA in PBS (with $2 \mathrm{mM} \mathrm{MgCl}_{2}$ ) for $20 \mathrm{~min}$ (TA muscles) at $4{ }^{\circ} \mathrm{C}$. After dehydration by $30 \%$ sucrose, muscles were frozen, cut into $80 \mu \mathrm{m}$ sections, and placed on gelatin-coated glass slides (Sangon Biotech, Shanghai, China). Diaphragms were fixed for $15 \mathrm{~min}$ and placed on gelatin-coated glass slides. Muscle sections and diaphragm (whole mount) were then washed with $\mathrm{PBS} / 2 \mathrm{mM} \mathrm{MgCl}$ for $10 \mathrm{~min}$ at $4{ }^{\circ} \mathrm{C}$, and incubated with the permeabilizing buffer containing $2 \mathrm{mM} \mathrm{MgCl}, 0.01 \%$ sodium deoxycholate, $0.02 \%$ $\mathrm{NP}-40$ in $0.1 \mathrm{M}$ phosphate buffer, $\mathrm{pH} 7.4$ for $10 \mathrm{~min}$ at $4{ }^{\circ} \mathrm{C}$. Samples were incubated with the staining solution (5 mM potassium ferrocyanide, $5 \mathrm{mM}$ potassium ferricyanide, $2 \mathrm{mg} / \mathrm{ml} \mathrm{X}$-gal in the permeabilizing buffer) at $37{ }^{\circ} \mathrm{C}$ overnight. It is important to keep $\mathrm{pH}$ at 7.4, which is optimal for recombinant b-gal, but not for endogenous b-gal in mammalian tissues whose optimal $\mathrm{pH}$ is acidic [67]. Samples were washed with PBS for $4-8 \mathrm{~h}$ at $37{ }^{\circ} \mathrm{C}$ or performed IHC, mounted, and subjected to Z-stack imaging. In some experiments, single muscle fibers were isolated by incubating muscles in $0.2 \%$ collagenase type I at $37{ }^{\circ} \mathrm{C}$ for $1 \mathrm{~h}$ with occasional shaking [68]. Dissociated muscle fibers were collected and fixed with $2 \%$ PFA for 5 min at RT, placed on gelatin-coated slides, and stained for X-gal and AChR.

\section{Cell culture}

Mouse C2C12 muscle cells and HEK293 cells were maintained as described previously [69]. They were transfected with $1 \mathrm{mg} / \mathrm{ml}$ PEI (polyethyleneimine, MW 40000, Polysciences, \#24765) in DMEM, as described before [27, 69].

\section{Real-time PCR}

Total RNA of muscles or C2C12 cells was extracted using Trizol (Sigma, \#15596018) and transcribed into cDNA templates using High-Capacity cDNA Reverse Transcription Kits (Sigma, \#4368813) following manufacturer's instructions. Quantitative PCRs were run by StepOnePlus ${ }^{\mathrm{TM}}$ Real-Time System (Applied Biosystems, Foster City, CA, USA) using PowerUp ${ }^{\text {TM }}$ SYBR Green Master Mix (Applied Biosystems, Life Technologies, Austin, TA, USA). The primers for specific genes were as follows: LRP4 (F: 5'-GTG TGG CAG AAC CTT GAC AGT C-3', R: 5'-TAC GGT CTG AGC CAT CCA TTC C-3'); MuSK (F: 5'-CTG AAG GCT GTG AGT CCA CTG T-3', R: 5'-TCC TTT ACC GCC AGG CAG TAC T-3); Rapsyn (F: 5'-GTG GAT GAA GGT GCT GGA GAA G-3',
R: 5'-CCG AGC AGT ATC AAT CTG GAC C-3); AChRe (F: 5'-AGA CCT GAG GAC ACT GTC ACC A-3', R: 5'-TCG TCC TTG CTG TAG TTG AGC C-3); AChR (F: 5'-CTT GTG GCT AAG AAG GTG CCT G-3', R: 5'-GCA AGG ACA CAT TGA GCA CGA C-3); LacZ (F: 5'-AAT CTG TCG ATC CTT CCC GC-3', R: 5'-TTA GCG AAA CCG CCA AGA CT-3); GAPDH (F: 5'-GTG AAG GTC GGT GTG AAC GG-3', R: 5'-CAA GCT TCC CAT TCT CGG CCT-3).

\section{Western blot analysis}

Lysates were prepared in RIPA buffer $(50 \mathrm{mM}$ Tris- $\mathrm{HCl}$, pH7.4, $150 \mathrm{mM} \mathrm{NaCl}, 2 \mathrm{mM}$ EDTA, $1 \%$ sodium deoxycholate, 1\% SDS, $1 \mathrm{mM}$ PMSF, $50 \mathrm{mM}$ sodium fluoride, $1 \mathrm{mM}$ sodium vanadate, $1 \mathrm{mM}$ DTT and protease inhibitor cocktails), as previously described [70, 71]. Samples were resolved on SDS-PAGE and transferred onto nitrocellulose membranes, which were incubated with Trisbuffered saline (TBS) with $0.1 \%$ Tween-20 (TBST) and $5 \%$ skim milk for $1 \mathrm{~h}$ at RT. Membranes were washed three times for 10 min before incubation with a primary antibody overnight at $4{ }^{\circ} \mathrm{C}$. After washing with TBST for three times, membranes were incubated with TBS containing HRP-conjugated secondary antibody for $1 \mathrm{~h}$ at RT. Immunoreactive bands were captured by Gel DocXR (Bio-Rad, Hercules, CA, USA) and band density was quantified by ImageJ.

\section{Denervation}

Denervation was performed as described previously [72] Briefly, adult mice were anesthetized with ketamine and xylazine cocktail (100 and $10 \mathrm{mg} / \mathrm{kg}$ body weight, respectively, i.p.). Disinfect and remove the hair between the thigh and the spinal cord and cut the skin to expose the sciatic nerve. The right sciatic nerve was removed a segment $(5 \mathrm{~mm})$, and the left sciatic nerve was subjected sham operation. Suture muscle and skin, and put the operated mice back into the cage. Pick up TA muscle at different time points (after denervation 1 day, 3 days, 5 days).

\section{Compound muscle action potential recording (CMAPs recoding)}

Compound muscle action potential recording was performed as described previously [35, 60, 73]. Mice were anesthetized with isoflurane continuously supplied by VetFlo anesthesia system (Kent Scientific) and placed on a $37{ }^{\circ} \mathrm{C}$ heating pad. One recording needle electrode (TECA, 092-DMF25-S) was inserted into the middle of the TA or GA muscle, another one as a reference needle electrode was inserted into the Achilles tendon, both of which were connected to AxoPatch 700B Amplifier (Molecular Devices). And two stimulation needle 
electrodes were inserted and close the sciatic nerve, and connected to an isolator (ISO-Flex, AMPI). The sciatic nerve was stimulated with a series of 10 stimulations (5 V, $0.2 \mathrm{~ms}$ ) at $1,5,10,20$, and $40 \mathrm{~Hz}$, and CMAP was recorded by Digidata1500B and analyzed by Clampfit 10.7 software (Molecular Devices).

\section{Electrical stimulation of muscle}

Mice were anesthesia with isoflurane continuously supplied by Low-Flow Anesthesia System (Kent Scientific, Torrington, USA) and placed on a $30-35^{\circ} \mathrm{C}$ plate (Aurora Scientific 1300A) to maintain the body temperature. Stimulation electrodes were inserted into the TA muscle, stimulated with a series pulse $(100 \mathrm{~mA}, 0.2 \mathrm{~ms}, 1 \mathrm{~s}, 5 \mathrm{~Hz}$ pulse for 50 times with a $10 \mathrm{~s}$ delay between each pulse) for 30 days by Aurora Scientific 1300A.

\section{In vivo tetanic force measurement}

Torque muscle tension analysis was performed on mice as described previously [74]. Briefly, mice were anesthetized with isoflurane continuously supplied by VetFlo anesthesia system (Kent Scientific) and placed on a $37^{\circ} \mathrm{C}$ heating pad. The knee was fixed on the clamp. The skin on the calf was cut to expose the TA muscle. The distal tendon of TA muscle was isolated with sharp tweezers and tied with a thin thread hanging onto the footplate connected to the servomotor (Aurora Scientific 1300A). The angle between the footplate and the tibia/fibula was usually at $90^{\circ}$. For muscle stimulation, two-needle electrodes were inserted subcutaneously into TA muscle. Firstly, identify the best stimulation strength $\left(\mathrm{C}_{\mathrm{BS}} \mathrm{mA}\right)$, a single electrical stimulation ( $0.2 \mathrm{~ms}$ pulse width) was given starting from $100 \mathrm{~mA}$, the muscle force was measured for every $30 \mathrm{~mA}$ increase, with an interval of $30 \mathrm{~s}$. When the muscle force was no longer increasing, the current was the best stimulation strength. And then, the best position of muscle contraction was found by adjusting the distance between the footplate and the clamp and measuring the muscle force by stimulating muscle with a single electrical stimulation $\left(\mathrm{C}_{\mathrm{BS}} \mathrm{mA}, 0.2 \mathrm{~ms}\right.$ pulse width). When the muscle force was no longer increasing, the position was the best position of muscle contraction. Then, under the best position and the best stimulation strength, the tetanic force was measured by stimulating muscle with a series of stimulations $\left(C_{B S} \mathrm{~mA}, 0.2 \mathrm{~ms}\right.$ pulse width, $300 \mathrm{~ms}$ duration) at 25, 50, 75, 100,125, 150, and $175 \mathrm{~Hz}$, with an interval of $2 \mathrm{~min}$. Tetanic forces were was recorded by DMCv5.500 and analyzed by DMAv5.300, normalized by body weight, and described as $\mathrm{N} / \mathrm{Kg}$.

\section{Statistical analysis}

Statistics were computed using GraphPad software. Data with two groups were analyzed using two-tailed paired or un-paired Student's t-test. For datasets with repeated measures and more than two groups, oneway or two-way ANOVA was used, followed by post hoc Bonferroni or Tukey's multiple comparison correction. Statistical significance was accepted at the 5\% significance level $(\mathrm{p}<0.05)$. Unless otherwise indicated, $>5$ mice per group or four or more dishes of muscle cells of one mouse were studied. Data are expressed as means \pm SEM.

\begin{abstract}
Abbreviations
a-BTX: Alpha-bungarotoxin; $\beta$-gal: $\beta$-Galactosidase; CMAP: Compound muscle action potential recording; EDL: Extensor digitorum longus; ECD: Extracellular domain; ICD: Intracellular domain; MuSK kd: MuSK kinase-dead; NF: Neurofilament; NMJ: Neuromuscular junction; qPCR: Quantitative polymerase chain reaction; SYN: Synapsin; TA: Tibialis anterior;WT: Wild-type.
\end{abstract}

\section{Supplementary Information}

The online version contains supplementary material available at https://doi. org/10.1186/s13578-021-00619-z.

Additional file 1: Figure S1. Characterization of MuSK K608A mice. a, Diagrams of MuSK gene. Lys608 (K608, AAG) mutants to Analine (A, GCA). b, Genotyping by sequencing with revise primer. c, Western blot showing protein level of MuSK and phosphorylated-MuSK using anti-MuSK antibody and anti-phosphotyrosine (4G10) antibody. d, Diaphragms of E17 mice of indicated genotypes were stained mount with a-BTX (red) and SYN/NF (green). Scale bar, 1 mm. Figure S2. No effect for synaptic nuclei aggregation in denervated muscle. Single fibers of EDL muscle were isolated with $0.2 \%$ collagenase type I and stained a-BTX (red) and DAPI (blue). a, Representative images of synaptic nuclei of denervated EDL muscles. Scale bar, $50 \mu \mathrm{m}$. b, Quantification of the number of synaptic nuclei. $n=10$ muscle fibers per group, $F(4,45)=0.2245$. One-way ANOVA followed by Tukey's multiple comparisons test. Data were shown as mean \pm SEM. Figure S3. The role of $\mu$-conotoxin. a, No change of CMAP amplitude ratio 10th/1 th in $\mu$-conotoxin treated TA muscle. $n=4$ mice per group, $F(1,30)=3.665 . p=0.0651$. $b$, Representative trace of the 1 th stimulated CMAP. c, Quantification of the 1th stimulated CMAP amplitude, $\mathrm{n}=4$ mice per group, ${ }^{* * *} \mathrm{p}=0.0003$. $\mathrm{d}$, Scheme of measuring TA muscle tetanic force. e, Decreased tetanic force under different frequency stimulation in $\mu$-conotoxin treated TA muscle. $n=3$ mice per group, $F(1,28)=$ 818.1, ${ }^{* * *} \mathrm{p}<0.0001$. f, Representative trace of tetanic force at $100 \mathrm{~Hz}$. a, e Two-way ANOVA followed by Bonferroni's multiple comparisons test; c, Two-tailed Independent Student's t-test. Data were shown as mean \pm SEM.

\section{Acknowledgements}

We thank Dr. Guanglin Xing and Dr. Nannan Gao for proofreading and revising grammatical errors in the manuscript, and members of our Lab for critical comments and constructive discussions.

\section{Authors' contributions}

HYJ, CP, XSL and BML contributed the design of the work; HYJ, CP, JZ, TKH and ZY contributed the acquisition of data; HYJ, CP, and XSL contributed the analysis of data; HYJ, ZJ, EKF, SQW, DYR and BML contributed the interpretation and discussion of data; HYJ, XSL and BML contributed the draft of the manuscript; $H Y J, E K F$ and BML contributed the revision of the manuscript. All authors read and approved the final manuscript.

\section{Funding}

This work was supported by the National Natural Science Foundation of China (31660268, 81601092) and Natural Science Foundation of Jiangxi Province (20181BAB215017). 


\section{Availability of data and materials}

The datasets used and/or analysed during the current study are available from the corresponding author on reasonable request.

\section{Declarations}

\section{Ethics approval and consent to participate}

Not applicable.

\section{Consent for publication}

Not applicable.

\section{Competing interests}

The authors declare that they have no competing interests.

\section{Author details}

${ }^{1}$ School of Life Science, Nanchang University, Nanchang 330031, China. ${ }^{2}$ Institute of Life Science, Nanchang University, Nanchang 330031, China. ${ }^{3}$ Human Aging Research Institute, Nanchang University, Nanchang 330031, China. ${ }^{4}$ Department of Psychology and Institute of Brain Science, School of Education, Hangzhou Normal University, Hangzhou 311121, China.

Received: 8 May 2021 Accepted: 25 May 2021

Published online: 05 June 2021

\section{References}

1. Fertuck HC, Salpeter MM. Localization of acetylcholine receptor by 125I-labeled alpha-bungarotoxin binding at mouse motor endplates. Proc Natl Acad Sci USA. 1974;71(4):1376-8.

2. Bevan $\mathrm{S}$, Steinbach JH. The distribution of alpha-bungarotoxin binding sites of mammalian skeletal muscle developing in vivo. J Physiol. 1977;267(1):195-213.

3. Li L, Xiong WC, Mei L. Neuromuscular junction formation, aging, and disorders. Annu Rev Physiol. 2018;80:159-88.

4. Zong Y, et al. Structural basis of agrin-LRP4-MuSK signaling. Genes Dev. 2012;26(3):247-58.

5. Zhang $B$, et al. LRP4 serves as a coreceptor of agrin. Neuron. 2008;60(2):285-97.

6. Kim N, et al. Lrp4 is a receptor for Agrin and forms a complex with MuSK. Cell. 2008;135(2):334-42.

7. Inoue A, et al. Dok-7 activates the muscle receptor kinase MuSK and shapes synapse formation. Sci Signal. 2009;2(59):ra7.

8. Weatherbee SD, Anderson KV, Niswander LA. LDL-receptor-related protein 4 is crucial for formation of the neuromuscular junction. Development. 2006;133(24):4993-5000.

9. Gautam M, et al. Defective neuromuscular synaptogenesis in agrindeficient mutant mice. Cell. 1996;85(4):525-35.

10. DeChiara TM, et al. The receptor tyrosine kinase MuSK is required for neuromuscular junction formation in vivo. Cell. 1996;85(4):501-12.

11. Gautam M, et al. Failure of postsynaptic specialization to develop at neuromuscular junctions of rapsyn-deficient mice. Nature. 1995;377(6546):232-6.

12. Brenner HR, Witzemann V, Sakmann B. Imprinting of acetylcholine receptor messenger RNA accumulation in mammalian neuromuscular synapses. Nature (London). 1990;344:544-7.

13. Fontaine $B$, Changeux JP. Localization of nicotinic acetylcholine receptor alpha-subunit transcripts during myogenesis and motor endplate development in the chick. J Cell Biol. 1989;108:1025-37.

14. Fontaine $B$, et al. Detection of the nicotinic acetylcholine receptor alphasubunit mRNA by in situ hybridization at neuromuscular junctions of 15-day-old chick striated muscles. EMBO J. 1988;7:603-9.

15. Goldman D, Staple J. Spatial and temporal expression of acetylcholine receptor RNAs in innervated and denervated rat soleus muscle. Neuron (USA). 1989;3:219-28.

16. Kues WA, et al. Local neurotrophic repression of gene transcripts encoding fetal AChRs at rat neuromuscular synapses. J Cell Biol. 1995;130:949-57.
17. Merlie JP, Sanes JR. Concentration of acetylcholine receptor mRNA in synaptic regions of adult muscle fibres. Nature (London). 1985;317:66-8.

18. Simon AM, Hoppe P, Burden SJ. Spatial restriction of AChR gene expression to subsynaptic nuclei. Development. 1992;114:545-53.

19. Klarsfeld A, et al. A 5' flanking region of the chicken acetylcholine receptor alpha-subunit gene confers tissue-specificity and developmental control of expression in transfected cells. Mol Cell Biol. 1987;7:951-5.

20. Gundersen K, Sanes JR, Merlie JP. Neural regulation of muscle acetylcholine receptor epsilon- and alpha-subunit gene promoters in transgenic mice. J Cell Biol. 1993;123:1535-44.

21. Sanes JR, et al. Selective expression of an acetylcholine receptor-lac $Z$ transgene in synaptic nuclei of adult muscle fibers. Development. 1991;113:1181-91.

22. Meier T, et al. Agrin can mediate acetylcholine receptor gene expression in muscle by aggregation of muscle-derived neuregulins. J Cell Biol. 1998;141(3):715-26.

23. Jones $\mathrm{G}$, et al. Induction by agrin of ectopic and functional postsynaptic-like membrane in innervated muscle. Proc Natl Acad Sci USA. 1997;94(6):2654-9.

24. Punga $A R$, et al. MuSK levels differ between adult skeletal muscles and influence postsynaptic plasticity. Eur J Neurosci. 2011;33(5):890-8.

25. Jones $\mathrm{G}$, et al. Substrate-bound agrin induces expression of acetylcholine receptor epsilon-subunit gene in cultured mammalian muscle cells. Proc Natl Acad Sci USA. 1996;93(12):5985-90.

26. Choi HY, et al. APP interacts with LRP4 and agrin to coordinate the development of the neuromuscular junction in mice. Elife. 2013;2:e00220.

27. $\mathrm{Wu} \mathrm{H}$, et al. Distinct roles of muscle and motoneuron LRP4 in neuromuscular junction formation. Neuron. 2012;75(1):94-107.

28. Kishi M, et al. LL5beta: a regulator of postsynaptic differentiation identified in a screen for synaptically enriched transcripts at the neuromuscular junction. J Cell Biol. 2005;169(2):355-66.

29. Zhang H, et al. Agrin-Lrp4-Ror2 signaling regulates adult hippocampal neurogenesis in mice. Elife. 2019;8:e45303.

30. Sun XD, et al. Lrp4 in astrocytes modulates glutamatergic transmission. Nat Neurosci. 2016;19(8):1010-8.

31. Yang $X$, et al. Patterning of muscle acetylcholine receptor gene expression in the absence of motor innervation. Neuron. 2001;30(2):399-410.

32. Lin W, et al. Distinct roles of nerve and muscle in postsynaptic differentiation of the neuromuscular synapse. Nature. 2001;410(6832):1057-64.

33. Dang Y, et al. RKI-1447, a Rho kinase inhibitor, causes ocular hypotension, actin stress fiber disruption, and increased phagocytosis. Graefes Arch Clin Exp Ophthalmol. 2019;257(1):101-9.

34. Patel RA, et al. RKI-1447 is a potent inhibitor of the Rho-associated ROCK kinases with anti-invasive and antitumor activities in breast cancer. Cancer Res. 2012;72(19):5025-34.

35. Zhao K, et al. Sarcoglycan alpha mitigates neuromuscular junction decline in aged mice by stabilizing LRP4. J Neurosci. 2018;38(41):8860-73.

36. Yumoto N, Kim N, Burden SJ. Lrp4 is a retrograde signal for presynaptic differentiation at neuromuscular synapses. Nature. 2012;489(7416):438-42.

37. Zhang $W$, et al. Agrin binds to the N-terminal region of Lrp4 protein and stimulates association between Lrp4 and the first immunoglobulin-like domain in muscle-specific kinase (MuSK). J Biol Chem. 2011;286(47):40624-30.

38. Wu H, Xiong WC, Mei L. To build a synapse: signaling pathways in neuromuscular junction assembly. Development. 2010;137(7):1017-33.

39. Lømo T, Slater C. Control of acetylcholine sensitivity and synapse formation by muscle activity. J Physiol. 1978;275(1):391-402.

40. Goldman D, Brenner HR, Heinemann S. Acetylcholine receptor alpha-, beta-, gamma-, and delta-subunit mRNA levels are regulated by muscle activity. Neuron. 1988;1(4):329-33.

41. Sato K, et al. Active site of mu-conotoxin GIIIA, a peptide blocker of muscle sodium channels. J Biol Chem. 1991;266(26):16989-91.

42. Patel RA, et al. RKI-1447 is a potent inhibitor of the Rho-associated ROCK kinases with anti-invasive and antitumor activities in breast cancer. Can Res. 2012;72(19):5025-34.

43. Park GB, Kim D. PI3K catalytic isoform alteration promotes the LIMK1related metastasis through the PAK1 or ROCK1/2 activation in cigarette smoke-exposed ovarian cancer cells. Anticancer Res. 2017;37(4):1805-18. 
44. Thompson JM, et al. Rho-associated kinase 1 inhibition is synthetically lethal with von Hippel-Lindau deficiency in clear cell renal cell carcinoma. Oncogene. 2017;36(8):1080.

45. Salmon AM, Changeux JP. Regulation of an acetylcholine receptor LacZ transgene by muscle innervation. NeuroReport. 1992;3(11):973-6.

46. Herz J, et al. Expanding functions of lipoprotein receptors. J Lipid Res. 2009:50(Suppl):S287-92.

47. Tintignac LA, Brenner HR, Ruegg MA. Mechanisms regulating neuromuscular junction development and function and causes of muscle wasting. Physiol Rev. 2015;95(3):809-52.

48. Henriquez JP, et al. Wnt signaling promotes AChR aggregation at the neuromuscular synapse in collaboration with agrin. Proc Natl Acad Sci USA. 2008;105(48):18812-7.

49. Zhang B, et al. Wnt proteins regulate acetylcholine receptor clustering in muscle cells. Mol Brain. 2012;5:7.

50. Masiakowski P, Yancopoulos GD. The Wnt receptor CRD domain is also found in MuSK and related orphan receptor tyrosine kinases. Curr Biol. 1998;8(12):R407.

51. Stiegler AL, Burden SJ, Hubbard SR. Crystal structure of the frizzled-like cysteine-rich domain of the receptor tyrosine kinase MuSK. J Mol Biol. 2009;393(1):1-9.

52. Messeant J, et al. MuSK frizzled-like domain is critical for mammalian neuromuscular junction formation and maintenance. J Neurosci. 2015;35(12):4926-41.

53. Jing $L$, et al. Wnt signals organize synaptic prepattern and axon guidance through the zebrafish unplugged/MuSK receptor. Neuron. 2009;61(5):721-33.

54. Remedio L, et al. Diverging roles for Lrp4 and Wnt signaling in neuromuscular synapse development during evolution. Genes Dev. 2016;30(9):1058-69.

55. Luo ZG, et al. Regulation of AChR clustering by Dishevelled interacting with MuSK and PAK1. Neuron. 2002;35(3):489-505.

56. Li XM, et al. Retrograde regulation of motoneuron differentiation by muscle beta-catenin. Nat Neurosci. 2008;11(3):262-8.

57. Wu H, et al. beta-Catenin gain of function in muscles impairs neuromuscular junction formation. Development. 2012;139(13):2392-404.

58. Liu Y, et al. beta-Catenin stabilization in skeletal muscles, but not in motor neurons, leads to aberrant motor innervation of the muscle during neuromuscular development in mice. Dev Biol. 2012;366(2):255-67.

59. Banziger $C$, et al. Wntless, a conserved membrane protein dedicated to the secretion of Wnt proteins from signaling cells. Cell. 2006;125(3):509-22.
60. Shen C, et al. Motoneuron Wnts regulate neuromuscular junction development. Elife. 2018;7:e34625.

61. Numberger $M$, et al. Different mechanisms regulate muscle-specific AChR gamma- and epsilon-subunit gene expression. EMBO J. 1991;10(10):2957-64.

62. Ham DJ, et al. The neuromuscular junction is a focal point of mTORC1 signaling in sarcopenia. Nat Commun. 2020;11(1):1-21.

63. Fromm L, Burden SJ. Synapse-specific and neuregulin-induced transcription require an ets site that binds GABPalpha/GABPbeta. Genes Dev. 1998;12(19):3074-83.

64. Khurana TS, et al. Activation of utrophin promoter by heregulin via the ets-related transcription factor complex GA-binding protein alpha/beta. Mol Biol Cell. 1999;10(6):2075-86.

65. Shen C, et al. Antibodies against low-density lipoprotein receptor-related protein 4 induce myasthenia gravis. J Clin Investig. 2013;123(12):5190-202.

66. Zhang B, et al. Wnt proteins regulate acetylcholine receptor clustering in muscle cells. Mol Brain. 2012;5(1):7.

67. Dimri GP, et al. A biomarker that identifies senescent human cells in culture and in aging skin in vivo. Proc Natl Acad Sci. 1995:92(20):9363-7.

68. Rosenblatt JD, et al. Culturing satellite cells from living single muscle fiber explants. Vitro Cell Dev Biol-Anim. 1995;31(10):773-9.

69. Zhang B, et al. $\beta$-Catenin regulates acetylcholine receptor clustering in muscle cells through interaction with rapsyn. J Neurosci. 2007;27(15):3968-73.

70. Chen $P$, et al. Spine impairment in mice high-expressing neuregulin 1 due to LIMK1 activation. Cell Death Dis. 2021;12(4):1-15.

71. Yin D-M, et al. Reversal of behavioral deficits and synaptic dysfunction in mice overexpressing neuregulin 1. Neuron. 2013;78(4):644-57.

72. Seltzer ZE, Dubner R, Shir Y. A novel behavioral model of neuropathic pain disorders produced in rats by partial sciatic nerve injury. Pain. 1990;43(2):205-18.

73. Gao N, et al. A role of lamin A/C in preventing neuromuscular junction decline in mice. J Neurosci. 2020;40(38):7203-15.

74. Hui T, et al. Increasing LRP4 diminishes neuromuscular deficits in a mouse model of Duchenne muscular dystrophy. Hum Mol Genet. 2021. https:// doi.org/10.1093/hmg/ddab135.

\section{Publisher's Note}

Springer Nature remains neutral with regard to jurisdictional claims in published maps and institutional affiliations.
Ready to submit your research? Choose BMC and benefit from:

- fast, convenient online submission

- thorough peer review by experienced researchers in your field

- rapid publication on acceptance

- support for research data, including large and complex data types

- gold Open Access which fosters wider collaboration and increased citations

- maximum visibility for your research: over $100 \mathrm{M}$ website views per year

At BMC, research is always in progress.

Learn more biomedcentral.com/submissions 